\title{
EL TEATRO DE MANUEL ANDÚJAR: CONTRIBUCIÓN A SU ESTUDIO ${ }^{1}$
}

\author{
JOSÉ RODRÍGUEZ RICHART
}

\section{INTRODUCCIÓN}

Manuel Andújar es considerado hoy generalmente como un gran novelista, a juicio de la mayoría de los críticos. Así Valbuena, al comentar Llanura insiste en su «verdadera potencia de escritor» y añade que en él «se percibe un recio y auténtico novelista» (Valbuena, 1983:426). O bien Eugenio de Nora, refiriéndose a $E l$ vencido, escribe que esa novela «basta para situar a Andújar entre los mejores narradores actuales» (Nora, 1962:275). Santos Sanz Villanueva, por su parte, más recientemente, le califica de «uno de nuestros más exigentes e importantes novelistas actuales» (Santos Sanz, 1977:146). Creo que es una verdad tan reconocida y aceptada que no parece necesario insistir en ello. Pero sí en el hecho de que, por pertenecer Andújar a los escritores españoles que marcharon al exilio en 1939, su obra novelística $-\mathrm{y}$ no digamos ya su obra poética o teatral o sus crónicas o relatos breves-, publicada casi toda ella en Méjico, empieza a ser gradualmente conocida sólo después de su retorno en 1967. Y así, las primeras novelas publicadas en España - las tres que forman la trilogía Vísperas - aparecen en Barcelona en 1970 con un prólogo de Rafael Conte. En él habla el crítico de la obra de Andújar como de un «descubrimiento» (Conte, 1970:17) y de que sus líneas prologales sólo pretenden presentar «a este escritor desconocido al público español» (Conte, 1970:19).

Si eso ha ocurrido con la novela de Andújar, su principal y más sobresaliente ocupación de escritor, mayor todavía es la ignorancia de su teatro, en parte porque ha tenido en su creación una dimensión marginal, como

\footnotetext{
${ }^{1}$ Quisiera agradecer aquí a Antonio Mancheño Ferreras y al Instituto de Estudios Jiennenses que hayan puesto a mi disposición fotocopias de las cuatro obras primeras de Manuel Andújar, publicadas en Méjico en 1942, de uno de los estudios de Piedad Bolaños y del de Samuel Gordon.
} 
en el caso de otros destacados escritores, famosos en otros géneros (pienso en Pedro Salinas, Manuel Altolaguirre, Ramón José Sender, José Herrera Petere, León Felipe, José Bergamín, Paulino Masip y algunos más) pero que, por diversos motivos, han cedido a la tentación escénica. El mismo Andújar habla de su teatro como un género literario «que no es el que más he cultivado» (Andújar, 1993:5) y califica sus obras escénicas de simples «merodeos teatrales» y de «teatrales escarceos» (Andújar, 1993:6). En parte también se debe esa ignorancia o desconocimiento a que sus primeras piezas teatrales (El Director General, Maruja, Estamos en paz y $Y$ después, ino grites!) $)^{2}$ se publicaron en Méjico en 1942 y las siguientes cronológicamente (El primer juicio final, Los aniversarios y El sueño robado) aparecieron también en Méjico en 1962, las cuatro primeras en una edición muy modesta de «Cuadernos del Destierro» y las otras tres en una mejor edición pero de sólo 600 ejemplares, según se indica en el colofón de esa misma edición (Andújar, 1962:160). Y en parte también, finalmente, porque, ya de vuelta a España, las obras teatrales que ha publicado lo han sido en revistas especializadas o periódicos locales (como Papeles de Son Armadáns o el Diario Jaén).

Las restantes obras escénicas (En la espalda, una X, Aquel visitante, Objetos hallados, Todo está previsto, Al minuto) junto con la reedición de El Director General, Los aniversarios y El sueño robado, han visto la luz en un volumen aparecido en 1993, en una cuidada edición de la Diputación de Jaén, con una introducción del propio autor. El hecho lamentable es que su producción teatral, como escribe acertadamente Piedad Bolaños, «ha sido prácticamente olvidada» (Bolaños, 1987a:XI).

\section{Visión GENERAL DEL TEATRO DE ANDÚJAR}

Así pues, la creación teatral de Manuel Andújar está constituida por doce obras, cuatro de ellas de larga extensión (El primer juicio final consta de un prólogo y tres actos, Los aniversarios de cuatro cuadros, Todo está previsto de un cuadro preliminar y tres actos y, finalmente, Al minuto de cuatro capítulos). Las demás son piezas breves: El Director General, Maruja y $Y$ después, ¡no grites!, tres «apuntes escénicos de la guerra española» constan de dos, de cuatro y de una escenas breves respectivamente; Estamos en paz, «ensayo dramático» también sobre el tema de la guerra civil y sus consecuencias, de cinco escenas cortas. El sueño robado

${ }^{2}$ Una análisis detallado de esas cuatro primeras obras de Andújar puede verse en Bolaños, 1987a: 155-161. De las pertenecientes al segundo grupo o etapa, la misma autora centra su análisis en El primer juicio final por considerarla representativa de esa etapa. Cfr. Bolaños, 1987a: 161-169. 
tiene un acto, En la espalda, una $X$, un acto, Aquel visitante, un acto de cuatro tiempos o escenas y Objetos hallados, un acto.

Que, por los motivos antes expuestos, hay todavía poca bibliografía sobre el teatro de Andújar, no es nada extraño y poco puede ayudarnos acudir en busca de más información a conocidos manuales o estudios porque en ellos, salvo alguna excepción, como máximo, sólo encontraremos - y no siempre de forma completa - la cita de algunos títulos de sus obras, en otros, ni siquiera eso. Pero, aunque poco, algo sí hay y entre las opiniones vertidas sobre la obra dramática de Andújar creo que hay que destacar el sustantivo prólogo del escritor ecuatoriano Demetrio Aguilera Malta («El teatro: un nuevo aspecto de Manuel Andújar» en Andújar, 1962) a la edición de tres obras del autor en 1962, las dos excelentes publicaciones de Piedad Bolaños en Andalucía y América en el siglo XX y en Anthropos, ambas de 1987, el trabajo de investigación de Samuel Gordon, de 1976, y las líneas que incidentalmente le dedica Rafael Conte en su prólogo a la edición de Vísperas (1970).

Pero la primera pregunta que se nos plantea al enfrentarnos con la creación teatral de un novelista es: ¿qué tiene de particular y de diferencial su teatro con respecto a su narrativa y qué tiene de común?

Que hay una diferencia considerable de perspectiva entre su novelística y su dramaturgia parece indudable y eso lo ha percibido bien Demetrio Aguilera. En el prólogo a las tres obras de Andújar aparecidas en Méjico en 1962 (El primer juicio final, Los aniversarios, El sueño robado) escribe lo siguiente: «en Andújar se está operando un singular fenómeno. Él, que siempre plasmaba sus creaciones con elementos realistas; que buscaba en la tierra, en sus hombres y en sus luchas, los fundamentos de su obra; que asía sus caracteres con la fuerza de la gravedad telúrica, ceñido y circunscrito a las cosas concretas y casi comprobables [...] tratando de buscar la verosimilitud hasta en su medio de expresión; él, decimos, hoy está espigando nuevos derroteros, nuevas fórmulas, nuevos métodos estéticos e, inclusive, nuevos géneros» (Aguilera, 1962:8). Esos «nuevos derroteros», esas «nuevas fórmulas», esos «nuevos métodos estéticos», sin suponer una ruptura radical con los anteriores - plasmados en sus novelas, relatos breves y crónicas - sí significan y entrañan un cambio que cristaliza ostensiblemente en su teatro. Este cambio de actitud de Andújar cree verlo el escritor ecuatoriano en una especie de «angustia cósmica» y escribe a este propósito: «tras su aparente tranquilidad, trepida un ser crucificado por todas las inquietudes y problemas del hombre frente a su destino, frente a los otros hombres y frente al infinito. Y que [...] empieza a experimentar un afán de investigación, al propio tiempo ecuménico y anímico, intemporal [...] que anhela intuir aquello que existe más allá del tiempo y de los tradicionales linderos de la verdad» (Aguilera, 1962:9).

Todas esas particularidades señaladas, efectivamente, parecen acertadas. 
Pero creo que debe hacerse una limitación importante: el realismo de las obras narrativas anteriores de Andújar («realismo del más autenticado, del que [...] arranca en nuestro país de Galdós y Leopoldo Alas», en opinión de Rafael Conte 1970:12), llevaba también soterrado el germen de esa evolución antes señalada. En su prólogo a Vísperas subraya Conte: «este realismo de Manuel Andújar [...] está elaborado a través de la construcción de símbolos morales, personajes o anécdotas que atravesando su propia significación real, se configuran como elementos de un juicio ético [...] Este dato [...] se observa con mayor claridad en otras de sus obras, en su teatro y en sus poemas, y determina, de alguna manera, sus características expresivas» (Conte, 1970:12-13).

A mí me ha resultado realmente sorprendente y hasta chocante contrastar, en función de los juicios y comentarios de Manuel Andújar vertidos en un artículo dedicado a la prosa narrativa de Jorge Campos, algunos aspectos de la evolución que seguramente ha experimentado el propio escritor andaluz. Habla en dicho artículo de las «persecuciones y exterminios racistas sin precedentes» (Andújar, 1978:87) (recuérdese que ése es uno de los temas centrales de su obra teatral Los aniversarios) y del «perpetrado lanzamiento de la bomba atómica y la amenaza nuclear» (Andújar, 1978:87) (recuérdese que ése es uno de los temas centrales de El primer juicio final). Y refiriéndose concretamente a los cuentos de Jorge Campos escribe el crítico Andújar: «La temática predominante [...] muéstrase de índole universal, de genérico interés humano, válida en cualquier latitud [...] y premonitoria de correlativo fatal porvenir cercano» (Andújar, 1978:88). Está casi describiendo o recordando lo que él mismo ha hecho o ha querido hacer con las piezas escénicas de la segunda etapa (a partir de las tres publicadas en 1962). Y aplica a Jorge Campos lo que, en realidad, se podría aplicar él mismo, ya que ésa ha sido también, aproximadamente, su andadura y su personal evolución: «A los impulsos y referencias realistas de sus volúmenes de relatos Tiempo pasado y El hombre y lo demás [...] les ha sucedido una cadena de ideaciones, grave capacidad de abstracción [...]. potencia imaginativa que, a manera de parábola [...] expone, y en términos de comunal vigencia humana, los dilemas contemporáneos, tan angustiosos que insolubles parecen» (Andújar, 1978:88).

También, en el propio escritor, parece haberse producido un cambio notable ya que, como estima Demetrio Aguilera, «los fines que persigue el dramaturgo Andújar no tienen que ver mucho con los del Andújar novelista, que bordeaba los linderos del realismo» y que «uno de los problemas que parecen dominarlo es el de la salvación - no sólo de las almas- sino de la especie humana» (Aguilera, 1962:10). En esta misma opinión coincide y abunda Rafael Conte cuando escribe: «El teatro [...] de Manuel Andújar explicita muy claramente esta significación moral [...] se despoja de su andamiaje realista y se hace más explícitamente ético» (Conte, 1970:14). 
Concluye el crítico que «la problemática del dramaturgo Manuel Andújar es inequívocamente ética» (Conte, 1970:15), localizando en sus condicionamientos personales e históricos -es decir, la preocupación por España, la severidad moral del escritor y el contexto histórico-literario en que se ha formado- las probables raíces de esta actitud.

La producción dramática de Andújar se podría clasificar, según Piedad Bolaños, «en dos etapas, predominando en la primera las obras con valor histórico y en la segunda con valor estético. "Al principio - dice nuestro autor- es patente la primacía de la motivación y naturales escozores políticos, unida al desgarramiento que nuestra guerra civil-internacional supuso para mí, junto al exacerbado sentir de otros compañeros de infortunio. Con los años prepondera - creo- una marcada evolución hacia modos y conflictos más de época'»(Bolaños, 1987a:XII) ${ }^{3}$.

\section{LOS ANIVERSARIOS}

Como ejemplo representativo del teatro de Andújar pensaba comentar aquí más al detalle algunos aspectos de una de las obras largas de su autor perteneciente a la segunda etapa, Los aniversarios, «la más perfecta a mi modo de ver», según Rafael Conte (1970:15), una de las de más entidad de toda su creación teatral y que muestra bien a las claras las posibilidades dramáticas de Andújar.

Los aniversarios consta de cuatro cuadros y nos presenta, en los dos primeros - que transcurren en Alemania en 1932 y en 1941/42 - la historia de un poeta judío alemán, el doctor Peter Sturm, que ha sido denunciado a las autoridades (en vísperas del advenimiento de Hitler al poder) por haber publicado un libro de versos en el que glosa estrofas sobre la libertad escritas por los clásicos alemanes. El primer juez, el doctor Leinecke, comprensivo y tolerante, se compadece de él y lo absuelve, aun a precio de tener que pedir después su propia jubilación. Pero Sturm tiene que comparecer de nuevo ante los tribunales y esta vez el juez es «un bárbaro joven vigoroso y despiadado, un esclavo de sus mitos huecos» (Andújar, 1962:112), un nazi típico que naturalmente le condena. Pero el poeta consigue huir de Alemania con su esposa, Ana, siendo acogido y encontrando refugio en Méjico. En Méjico tienen lugar los dos cuadros siguientes: en 1945 el primero y en 1947 el segundo. En 1945 se celebra un acto en

\footnotetext{
${ }^{3}$ Unas observaciones a este respecto. La cita de Andújar pertenece a una carta que el escritor dirigió a Piedad Bolaños el 6 de febrero de 1986 (Bolaños, 1987a:153). Las obras «con valor histórico» son las cuatro sobre la guerra civil española, teatro político en realidad, y en cuanto a los restantes obras «con valor estético» - segunda etapaquizá convenga precisar que, como acabamos de ver, tan importante o más es su carácter ético.
} 
honor del poeta para conmemorar el primer aniversario de su muerte y acuden a él muchos miembros de la colonia alemana de refugiados en Méjico. Pero dos años después, en el tercer aniversario, Ana, su viuda, sólo constata la tristeza del olvido, el desamparo de los muertos y la indiferencia de los demás. Casi nadie se acuerda ya de Peter Sturm, sólo Ana sigue conservando su memoria y su amor auténtico por él.

Un tema central de la obra, pues, es el de las persecuciones nazis y sus consecuencias, el antisemitismo hitleriano de que es víctima ese joven poeta judío alemán. Quizá haya querido simbolizar Andújar en ese poeta judío, en general, a los desterrados de todos los países por causas políticas o ideológicas, como ocurrió en su caso y en el de otros miles y miles de españoles que encontraron también en Méjico una fraternal acogida. Otro tema, más abstracto, es el sino, el destino del poeta desterrado, el desamparo, la soledad y el olvido en que viene a acabar su efímera fama, ante la fría indiferencia de los compatriotas, tema que, si lo interpreto correctamente, entrañaría un escepticismo y un pesimismo en su autor ${ }^{4}$ aunque compensado ciertamente por la firmeza y permanencia del amor de Ana, cada vez milagrosamente más ferviente.

En esta obra se puede apreciar bien, por otra parte, el relativo cambio de perspectiva del Andújar dramaturgo con respecto al Andújar novelista, visible ya en que no es un tema derivado del gran tema esencial y permanente de sus obras en prosa, es decir, España, la problemática española y la guerra civil ${ }^{5}$ sino que ahora son otros los personajes (alemanes, austriacos), son otras las causas históricas de su destierro, es otra la guerra a la que se hace referencia y otras las ideologías que la determinan, otros también los temas, en definitiva, aunque no podemos olvidar que se trata de un destino comparable (el de los desterrados, expatriados, exiliados o transterrados, al fin y al cabo).

«Andújar no ha sido tentado por otros asuntos que los españoles, a excepción de la temática mejicana de Partiendo de la angustia», escribe Santos Sanz Villanueva (Santos Sanz, 1977:147). Esta afirmación, válida para la prosa, no es, como vemos, válida para el teatro, ya que, aparte del ejemplo que comentamos - de temática alemana - en otras varias de las obras dramáticas de Andújar, por ejemplo en El primer juicio final, la temática es absolutamente internacional, universal, o en Todo está previsto

\footnotetext{
${ }^{4}$ Después de escrito esto, leo la siguiente cita de Otaola: «en el fondo de su alma - la de Andújar - hay mucha melancolía, mucho escepticismo, mucha esperanza muerta». La librería de Arana, México, El Aquelarre, 1952 (citado por J. R. Marra López, 1963:447). Unas páginas más adelante escribe Marra López, refiriéndose a Llanura y El vencido: «Aquéllas [...] poseían [...] una amargura y un pesimismo radicales» (Marra López, 1963:473).

5 «la preocupación por su patria, por la compleja problemática hispana (es) el motor fundamental de la obra del escritor» (Conte, 1970:11), hecho bien visible especialmente en las cuatro obritas de la primera etapa del teatro del autor, podríamos añadir.
} 
que el autor localiza en escenarios iberoamericanos - Caracas y Buenos Aires-, la temática es también de índole general y sólo en lo que afecta a los personajes Belén y Aníbal es parcialmente española.

Pero justamente en esos cambios o variaciones temáticas frente al tema casi permanente y primordial de su prosa se puede detectar y calibrar la evolución en la trayectoria de Andújar a que aludía en su comentario antes citado Demetrio Aguilera. Aunque naturalmente no todo es innovación, ya que las nuevas tendencias, orientaciones y preocupaciones se conjugan y perviven con las anteriores. Creo que en la presente obra se puede hablar de tres temas principales:

a) el del exilio o destierro, que aparece aquí en primer plano, es un tema recurrente y reaparece en otras varias obras teatrales del autor (en El Director General, José y Adelaida, en Todo está previsto, Belén y Aníbal, en Al minuto, Lucas, en El sueño robado, Abel);

b) el poeta y su destino, vinculado con el anterior, aflora en otras varias de las piezas de Andújar, por ejemplo en El Director General (José), un papel más importante tiene en El primer juicio final (el poeta abstracto $=$ Laender), también en Aquel visitante (Baldomero);

c) los judíos alemanes son en la obra, probablemente, un símbolo de los desterrados por antonomasia, como en Max Aub (recuérdese su San Juan o De algún tiempo a esta parte).

Los aniversarios es una obra convincente por su técnica, por la psicología y caracterización de sus personajes pero especialmente por su lenguaje, realmente notable, preciso y expresivo, perfectamente adaptado a las necesidades dramatúrgicas sin perder por eso su acento ocasionalmente poético (en boca de Peter Sturm). En el lenguaje del teatro, pues, se muestra de nuevo lo que ya conocíamos en su prosa, aunque aquí es más sobriamente refrenado: «un universo artístico montado sobre la delectación en el uso lingüístico, en el cuidado del estilo, en la casi amorosa orfebrería de su prosa, ante la que es imposible olvidarnos del Andújar poeta», escribe Pilar Palomo (Valbuena, 1983:428). Rafael Conte coincide con estas apreciaciones: «su prosa, trabajada, atirantada y tremendamente expresiva, anclada en la realidad del idioma popular pero transmutada por una deliberada voluntad de esquematización estilística» (Conte, 1970:16). Unas líneas más abajo insiste el crítico en la «deliberada y magnífica voluntad de estilo de Manuel Andújar, patente en todas sus obras [...] Hay estilo en Andújar, un estilo potente, expresivo» (Conte, 1970:16) ${ }^{6}$.

${ }^{6}$ Santos Sanz sitúa a Andújar «entre los escritores con una gran preocupación formal y nunca sujeto al fácil recurso del molde encontrado» (Santos Sanz, 1977:149). Así es, en efecto, en la prosa y así es también en el teatro. 


\section{FINAL}

Tenemos que terminar esta aproximación a la dramaturgia de Manuel Andújar, respecto a la que casi todo está todavía por hacer, como, por lo demás, está por hacer casi todo lo referente al teatro español del exilio, a pesar de su indudable importancia ${ }^{7}$. Precisamente dar a conocer en España y en otros países, lo poco conocido (o lo mucho desconocido) de ese valioso teatro del exilio ha sido una de mis preocupaciones constantes desde hace muchos años, como puede verse en mis trabajos sobre el teatro de Pedro Salinas, Alejandro Casona o Max Aub, entre otros ${ }^{8}$.

Quizá convenga tener presente aquí dos opiniones. Primero la de Francisco Ruiz Ramón, gran especialista del teatro español, que aunque se refiere solamente a las tres obras de Andújar publicadas en Méjico en 1962 (El primer juicio final, Los aniversarios, El sueño robado) -únicas que cita- creo que puede aplicarse a las restantes obras dramáticas, en especial a las de la segunda época o etapa: «El teatro de Andújar, de gran calidad y belleza literarias, pero — con excepción de El sueño robadomás cercano al relato dialogado y escenificado que a la construcción dinámica de la pieza teatral, es fundamentalmente un teatro de ideas, muy intelectual, de complejo simbolismo, de acción interior dialéctica, de perso-

\footnotetext{
7 «Resulta cada vez más evidente que uno de los elementos fundamentales, y por ende inexcusables, para el estudio de la literatura española producida después de la guerra civil, es el exilio», escribe, por ejemplo, Ángel Berenguer (Berenguer, 1977:1). Después de escrito este trabajo se ha publicado un libro importante que viene a llenar muchos vacíos existentes en el estudio de la creación dramática española exiliada. Se trata del volumen colectivo Manuel AZNAR SOLER (ed.): El exilio teatral republicano de 1939, Associació d'Idees-Gexel, Sant Cugat del Vallés (Barcelona), 1999. El Gexel (Grupo de Estudios del Exilio Literario) de la Universidad Autónoma de Barcelona, que tan meritoria y eficazmente está abordando el exilio cultural español del 39 en muchos de sus aspectos relevantes, ha publicado ya varias obras sobre este amplio tema y anuncia otras más, entre ellas un ambicioso Diccionario bio-bibliográfico sobre el exilio literario español de 1939.

8 «Sobre el teatro de Pedro Salinas», Boletín de la Biblioteca de Menéndez Pelayo, Santander, núm. 4, 1960, pp. 397-427, Vida y teatro de Alejandro Casona, Instituto de Estudios Asturianos, Oviedo, 1963, edición de La dama del alba de A. Casona, primero en Editorial Alcalá, Madrid, 1965, y posteriormente en Ediciones Cátedra, Madrid, (18. ${ }^{a}$ ed.) 2000, «Sobre Tres diamantes y una mujer de A. Casona», Segismundo, Madrid, 1965, pp. 343-357, «Casona en Norteamérica», Boletín del Instituto de Estudios Asturianos, Oviedo, núms. 57 y 58, 1966, pp. 147-203 y 145-190 respectivamente, «En torno al teatro español del exilio», Boletín de la Asociación Europea de Profesores de Español, Madrid, núm. 17, 1977, pp. 131-139, edición de Corona de amor y muerte, de A. Casona, Editorial Alcalá, Madrid, 1986, «Francia en la vida y en la obra de Max Aub», Revista de Literatura, Madrid, núm. 113, 1995, pp. 181-192, «Max Aub y Alemania», en Cecilio Alonso (ed.): Actas del Congreso Internacional Max Aub y el laberinto español, Ajuntament de Valencia, 1996, t. I, pp. 203-217.
} 
najes arquetípicos [...]. Su lenguaje tiene una pureza, una precisión y un ritmo clásicos.» (Ruiz Ramón, 1975:437).

Por su parte, Samuel Gordon, basándose también en las mismas tres piezas aparecidas en Méjico en 1962 y especialmente en la posterior Aquel visitante, opina que «Los dramas de Manuel Andújar se presentan con una prosa vibrante y condensada, que obliga a un gran esfuerzo de concentración - no siempre viable para un espectador teatral- y admitiendo la severidad estilística rectora del dramaturgo al rechazar toda clase de fórmulas, su potente lenguaje reúne, obviamente, vicios y virtudes» (Gordon, 1976:20). Más adelante, completando este juicio, añade lo siguiente: «buena parte de los mismos (se refiere a los recursos metafóricos) no se desvela ante el público sino que son susurrados al oído atento del lector del texto teatral [...] (y) denotan el hábito de buscar la complicidad y captación de un lúcido lector solitario antes que de un público teatral» (Gordon, 1976:33), señalando así cierta tendencia de este tipo de teatro a convertirse más en «teatro para leer» que en teatro representable.

El teatro de Manuel Andújar es un teatro con un sello incuestionable de originalidad, con temas e ideas de raíz profundamente humanística, con un sorprendente y hasta desbordante nivel imaginativo, con un noble sentido ético y con una expresión lingüística de una gran plasticidad y riqueza. Un teatro, por otra parte, no siempre fácil ni accesible, resistente a la interpretación, quizá carente de espectacularidad y por ello de posibilidades de ser estrenado con éxito - ninguna de sus obras ha sido estrenada hasta ahora por compañías profesionales- pero extraordinariamente valioso, personal y digno complemento, a mi entender, de la creación novelística de su autor.

\section{BIBLIOGRAFÍA}

1. Aguilera Malta, Demetrio: «El teatro: un nuevo aspecto de Manuel Andújar». Prólogo al volumen de teatro de Manuel Andújar que contiene tres obras: El primer juicio final, Los aniversarios y El sueño robado. Ed. de Andrea, México, 1962, pp. 7-11.

2. ANDÚJAR, Manuel: Teatro (contiene las tres piezas indicadas arriba). México, Ed. de Andrea, 1962.

3. ANDÚJAR, Manuel: Teatro. (Contiene ocho obras: El Director General, En la espalda, una $X$, Los aniversarios, El sueño robado, Aquel visitante, Objetos hallados, Todo está previsto y Al minuto). Lleva una introducción del propio Andújar. Jaén, Diputación Provincial de Jaén, 1993.

4. ANDÚJAR, Manuel: «Aproximación a la narrativa de Jorge Campos». Arbor, Madrid, núm. 395, 1978, pp. 87-94 
5. BeRENGUER, Ángel: «Veinticinco años de exilio en el teatro español contemporáneo». Ínsula, Madrid, núm. 371, 1977, pp. 1 y 10.

6. Bolaños, Piedad: «El teatro de Manuel Andújar. Ensayo interpretativo.» Andalucía y América en el siglo XX. Actas de las VI Jornadas de Andalucía y América. Sevilla, 1987a, pp. 155-169.

7. Bolaños, Piedad: «Una aproximación semiológica a Aquel visitante». Anthropos, núm. 72, 1987b, pp. XI-XVI.

8. CONTE, Rafael: «El realismo simbólico de Manuel Andújar». Prólogo a Vísperas. Ed. Andorra, Barcelona, 1970, pp. 9-19.

9. GoRdon, Samuel: Cuando la metáfora se disuelve en dramaturgia. (Una aproximación al teatro de Manuel Andújar). Universidad Hebrea de Jerusalén, 1976.

10. MARRA LÓPEZ, José Ramón: Narrativa española fuera de España (1939-1961). Ediciones Guadarrama, Madrid, 1963.

11. NORA, Eugenio de: La novela española contemporánea. Ed. Gredos, Madrid, 1962.

12. RuIZ RAmón, Francisco: Historia del teatro español. Siglo XX. Madrid, Cátedra, 1975.

13. RUIZ RAMÓN, Francisco: Estudios de teatro español clásico y contemporáneo. Fundación Juan March/Ediciones Cátedra, Madrid, 1978.

14. SanZ Villanueva, Santos: «La narrativa del exilio» en J. L. ABellán (ed.) El exilio español de 1939. Ed. Taurus, Madrid, 1977, pp. 146-150.

15. VAlbUENA PRAT, Ángel: Historia de la literatura española. Tomo VI: Epoca contemporánea. 9. ${ }^{a}$ ed. ampliada y puesta al día por María del Pilar Palomo. Ed. G. Gili, Barcelona, 1983.

16. Varios autores: Diccionario de Literatura española e hispanoamericana. Dirigido por Ricardo Gullón. Alianza editorial, Madrid, 1993. 